\title{
Transformation of Digital Ecosystems: The Case of Digital Payments
}

\author{
Stefan Henningsson and Jonas Hedman \\ Department of IT Management, Copenhagen Business School, Denmark \\ \{sh.itm,jh.itm\}@cbs.dk
}

\begin{abstract}
In digital ecosystems, the fusion relation between business and technology means that the decision of technical compatibility of the offering is also the decision of how to position the firm relative to the coopetive relations that characterize business ecosystems. In this article we develop the Digital Ecosystem Technology Transformation (DETT) framework for explaining technologybased transformation of digital ecosystems by integrating theories of business and technology ecosystems. The framework depicts ecosystem transformation as distributed and emergent from micro-, meso-, and macro-level coopetition. The DETT framework consists an alternative to the existing explanations of digital ecosystem transformation as the rational management of one central actor balancing ecosystem tensions. We illustrate the use of the framework by a case study of transformation in the digital payment ecosystem.
\end{abstract}

Keywords: Digital ecosystem, Coopetition, Payments, Transformation.

\section{Introduction}

Digital artefacts, including music, books, tickets, social media and money, hold increasingly prominent positions in the life of individuals, organizations, and society at large. An ongoing digitalization makes more and more industries fused with digital technologies (henceforth referred to as digital industries) (Tilson et al., 2010).

Digital industries present typical characteristics that set them apart from other industries. Traditional metaphors such as the value chain (Porter 1985) have been found inadequate to capture the actor relationships of digital industries (Stabell and Fjeldstad 1998). Digital industries are characterized by tension between competition and collaboration among actors (Ghazawneh and Henfridsson 2012). While some of the actors are direct competitors, they are also mutually dependent on the success of the industry as a whole. Digital industries are therefore conceived as digital ecosystems (Basole and Karla 2011). A business ecosystem is a coopetitive environment in which symbiotic relationships are formed to create mutual value for its members (Walley, 2007; Moore, 1996). Digital ecosystems (Selander et al., 2013; Ghazawneh \& Henfridsson, 2012; Yoo et al., 2012) are ecosystems characterized by a fusionrelation to digital technologies (c.f. Sawy 2003). The fusion of technology makes digital ecosystems transforming along with technological innovations that transforms the business landscape (Evans et al., 2006; Yoo et al., 2008). 
This paper contributes to the explanation of how the fusion-relationship between business and technology in digital ecosystems affects ecosystem transformation. Explicitly and implicitly, the extant literature on digital ecosystems has in general assumed a perspective on ecosystem transformation as the central actors' management of competitive and collaborative ecosystem tensions (e.g. Shane 2001; Ghazawneh and Henfridsson 2013). For some digital ecosystems, transformation is a much more distributed process, where transformation is emergent. Such transformation is, for example, much emphasized in the literature of digital infrastructures (Tilson et al., 2010; e.g Hanseth \& Lyytinen, 2010; Henningsson \& Zinner Henriksen, 2011) and the literature on technology ecosystems (Adomavicius et al., 2007). Addressing the need for a more distributed and emergent explanation to digital ecosystem transformation, we integrate ecosystems framework from the business and technology domains into a Digital Ecosystem Technology Transformation (DETT) framework. The result is a multi-level framework that depicts technology-based transformation as micro-, meso-, and macro-level business and technology innovation positioning.

To illustrate the framework's use, we apply it on one digital ecosystem which transformation cannot be understood from the position of one central actor's rational governance: the digital payment ecosystem. For centuries the evolution of payments was slow and strictly controlled. Now, partly due to the fusion with digital technologies, payments have become one of society's most innovative and dynamic sectors, with fierce technology-based competition. In this ecosystem, ecosystem transformation is the emerging result of strategic decisions from all ecosystems members on how to align technological innovations with the ecosystems installed base.

\section{Related Literature and Framework Development}

Taking departure in the view of digital industries as digital ecosystems, this section develops the DETT framework for explanation of technology-fused transformation of digital ecosystems. It is emphasised that the transformation cannot be fully conceived by approaching either business or technology strategy in isolation. Rather, both entities have to be conceived as the wider ecosystems of which they form part (Adomavicius et al. 2007).

At the core of our framework lies the notion of technical compatibility, where technical innovations form part of technical systems. In a market fused with digital technologies, the decision of compatibility borders becomes inseparable from business ecosystem positioning. Elaborating on this fundamental idea, we integrate the literature on business ecosystems (Moore 1996; Tansley 1935) with the literatures on compatibility and system-based competition (Adomavicius et al. 2007).

\subsection{Business Ecosystems}

We define an ecosystem as a coopetitive environment in which symbiotic relationships are formed to create mutual value for its members (Selander et al. 2010). In the literature, two features of ecosystems stand out (Selander et al. 2010). First, an 
ecosystem is characterized by simultaneous competition and cooperation, so called coopetition (Walley 2007). A micro-level of analysis depicts some actors as direct competitors, while a macro-level of analysis depicts the same actors as mutually dependent on the success of the ecosystem as a whole and are therefor forced into collaboration with other entities.

Ecosystems are not homogenous constructs. Within a business ecosystem, certain actors can have closer relations than other actors. One can even talk about ecosystems of ecosystems, or ecologies (García-Marco 2011). However, from this position the issue arises of how to handle the within-ecosystems clusters of actors that are more tightly connected than others. Within ecosystems, actors might form partnerships, alliances, networks and other formal and informal clusters that as a group have coopetive relations to other clusters. To capture this level of coopetive relations, a mesolevel of analysis is required. The meso-level of analysis depicts situations where more than one, but not all, actors of an ecosystem form business clusters that have coopetive relations to other clusters.

The second typical characteristic of ecosystems is that ecosystems are dynamic entities that constantly evolve. Continuous re-adaptations in the relationships between ecosystem members across micro-, meso-, and macro-levels make ecosystems dynamic. The systemic properties of the ecosystem means that changes in one of the ecosystems entities will trigger response and changes in other entities in a constantly dynamic process (Selander et al. 2011).

\subsection{Technology-Fused Business Ecosystems}

Previous research has observed that digital ecosystems transform rapidly along with technological innovations that alter conditions for the business landscape (Evans et al. 2006; Yoo et al. 2008; Zammuto et al. 2007). New technology generations are fundamentally reshaping the traditional logic, as business processes become intertwined with surrounding technology ecosystems (Basole 2009).

A digital ecosystem is an ecosystem that exists in a fusion-relation (c.f. Sawy 2003) to mobile technologies, where digital technologies form part of a 'technology ecosystem'. Adomavivious et al. (2007 p. 201) define a technology ecosystem as " $A$ system of interrelated technologies that influence each other's evolution and development." The definition is based on the view of evolving components of complex technologies as mutually interdependent (Iansiti et al. 1995). Consequently, from the consumer side, the selection of a specific technology is associated with a strategic decision to join a particular business network that operates in a specific technological 'regime' with interoperable technologies (Shane 2001). For the digital ecosystem actors, the fusion relation between business and strategy means that the collaborative and competitive strategies are inseparable from the strategic adoption of technology.

\subsection{Technology-Based Transformation in Digital Ecosystems}

The two sections above have established digital ecosystems as business ecosystems, and analysed the effects of technological compatibility on ecosystem positioning. 
Here, we draw on the conclusions made to develop the integrative DETT framework. The developed framework is divided into micro-, meso- and macro-levels as presented in Figure 1. Competition and collaboration exist on all three levels, and so do classes of compatible and incompatible technology. Consequently, technology-based transformation in digital ecosystems can be understood as a three-levelled process based on technology positioning:

- Micro-level, individual business units compete through proprietary technologies.

- Meso-level, strategic clusters are formed through shared technologies.

- Macro-level, the ecosystem of interdependent members as a whole competes with other ecosystems through technology regimes.

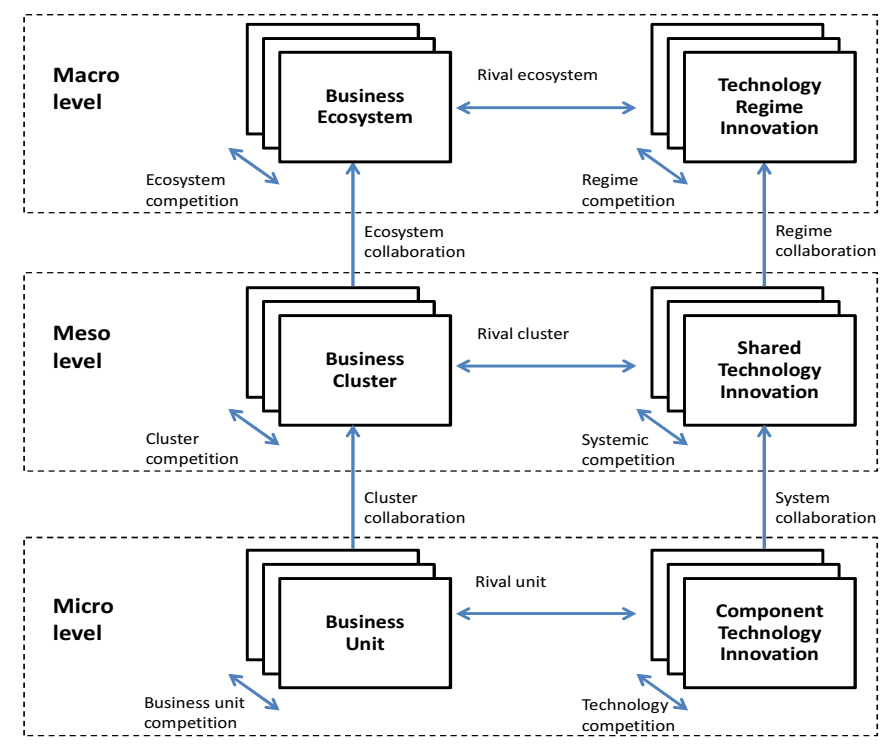

Fig. 1. Digital Ecosystem Technology Transformation Framework

Members contribute to the ecosystem technologies by innovation and adoption either in competitive or collaborative mode. In the collaborative mode, members on micro-, meso-, or macro-levels jointly innovate and/or adopt component, application, or support technologies that will benefit the members in the collaboration. Conversely, in the competitive mode members on the micro level innovate and/or adopt component, application, or support technologies that will benefit the specific member. The meso-level adoption is a situation of combined competition and collaboration mode.

\section{$3 \quad$ Method}

\subsection{Research Approach and Case Selection}

Empirically, this paper is based on a case study of the payment ecosystem in Denmark consisting of three embedded cases of digital payment innovations. The case 
study approach is suitable when studying contemporary phenomenon with unclear borders between phenomenon and its real-life (Yin 1984). Another important reason for applying the case study is that cases can be viewed as a series of experiments and thereby allowing for replication logic (Yin 1984). This is here achieved by three embedded cases that replicate findings across analytical levels. In practice, this means that each case is analysed in relationship to the initial framework and additional cases are used to challenge the insights gained from the previous cases. The insights grow with each case and allows for the emergence of theory and understanding.

There are two main reasons why we chose the digital payment ecosystem as empirical domain for illustrating our framework. First, the payment ecosystem is currently highly turbulent and unstable, as it searches for a new equilibrium as technologyfused ecosystem. Payments, with increasing frequency, consist of digital representations of money that are transferred in a global intertwined system that involve multiple parties, including payers, payment services providers, banks, telecom operators, mobile phone manufactures, and payees. This allows for identification and investigation of ongoing strategies on all levels of the DETT framework. Second, the payment ecosystem is central in today's society. This makes payments the battleground for one of the most important societal clashes of the 21 st century (Ondrus and Lyytinen 2011).

In our case study, we have chosen to focus on three technological innovations, and their associated business strategies, that are being used for entering the Danish payment market on micro-, meso-, and macro level. They are iZettle (a payment dongle invented by a startup), SMS payments (a payment service from mobile operators), and PayPal (a potential ecosystem contender).

\subsection{Data Collection and Analysis}

We used documents, interviews and workshops as empirical sources. Documents were official documents from Denmark and the European Union on the payment ecosystem (Danmarks-Nationalbank, 2005; Kokkola, 2010), and publicly available sources, such as annual reports, press releases, research articles, and web pages. One of the authors took part in six workshops on future payment technologies, organized by the financial industry in Denmark. Notes were taken during the workshops, which were later expanded after the session. Interviews with eight representatives from various ecosystem members were conducted. Interviews were recorded and transcribed.

When analysing the cases, the empirical observations were matched and compared with the DETT framework and its concepts, cf. Yin's (1984) pattern-matching technique. Being a case study, we aimed for generalizing towards theory (rather than population) and used the empirical findings to challenge existing frameworks and concepts related to evolution of payment ecosystem.

\section{Framework Illustration}

The introduction of the Eurozone, SEPA (Kokkola 2010), and changing payment behaviour (Evans and Schmalensee 2005) has drastically changed the payment 
landscape over the last decade (Garcia-Swartz et al. 2006). The main current development in the payment market is the replacement of the physical payment infrastructures with a digital payment infrastructure. This process started with payment cards and continued with internet and mobile banks. The digitalization of payments has changed the previously stable market. New actors emerge competing with technological innovations. Telecom operators are aggressively trying to get mobile payments onto their technical infrastructure. Many of these innovations are tied to new technologies. Banks all over the world are talking about "the new normal" or "the new standards". For centuries the evolution of payments was slow and strictly controlled. Now, payments have become one of society's most innovative and dynamic sectors.

\subsection{Micro Level Competition - iZettle}

Starting at the micro level, the payment ecosystem is experiencing the introduction of new technological innovations, including smartphone payment card dongles. This technology competes with card terminals or electronic funds transfer at point of sale (EFTPOS) that has existed since the mid 1980s. Traditionally payment card clearinghouses, such as Nets and Point, offer card terminals to merchants against a monthly fee and percentage of the transaction volume. Nets defend its market position through its monopoly. They are the only one allowed, by law, to process Dankort transactions and they invest heavily in their payment infrastructure. The merchant provides the payer with a terminal, provided by Nets or Point, so they can swipe their card. The EFTPOS establish a link to the payment card clearinghouse, which checks whether the card is valid and if there are any available funds. Then the payer approves the transaction through a pin code. There were about 220.000 card terminals that managed close to one billion card transaction in 2010.

Over the past few years a contender to the EFTPOS has emerged from startups in USA and Sweden, including companies such as Square from the USA (www.square.com) and iZettle from Sweden (www.izettle.com). iZettle entered the Danish market in 2011 and offers smartphones owners a dongle, which converts smartphones into EFTPOS. iZettle is registered as payment service providers, but not as a financial institution. Consequently, they do not work under the same laws and rules as, for instance, a bank. iZettle applies a battering ram strategy by offering similar functionality as a traditional EFTPOS, but with a low fixed costs to small businesses and private persons and charges $2.75 \%$ of each transaction. The offering disrupts the market by providing functionality to new market segments. For small merchants they offer a small point of sale system (POS). Nets and Point do not provide this service to is customers.

The dongle is compatible with existing smartphone communication ports. It uses the same installation procedure as for any software on a smartphone (AppStore or Goggle Play). The startup exploits the diffusion and the capabilities of smartphones. Howeverm this requires collaboration and partnership with Apple and Google to deploy the applications to the smartphone. Furthermore they collaborate with the Mastercard and VISA to accept these cards. They also collaborate with payment clearinghouses to verify the card and transaction. As a response the establishment, 
Nets, has launched MobilePenge - person-to-person account transfers through SMS with a $7 \%$ transaction fee. Nets draw upon its existing network of banks and its control of NEM-Konto to increase the barriers of entry on this market.

\subsection{Meso Level Competition - SMS Payments}

At the meso level we find the mobile operators who provide SMS payments. This type of payment is based on text messaging service in mobile communication systems. The SMS standard is part of the Global System for Mobile Communications (GSM) series of standards. The problem that SMSs solved was to send notifications to and from mobile phones, e.g. to inform of voice mail messages. Nokia was the first phone manufacturer to implement the standard back in 1993. Since then, the use of SMS has exploded in volume, in 2010, 6.1 trillion SMS were sent, and the roles have changed from notifications to a tool for personal communication, accessing digital content, and making payment.

The Finnish mobile operator Saunalahti (now part of Elisa Group) introduced SMS payments in 1998, when they offered the world's first downloadable ring tones. Today it is used for online payments, mobile application stores, bus tickets, and parking tickets. SMS payments use premium-rate telephone numbers for which prices are higher than normal. The provider of SMS payments uses either the telecom operators, such TDC, TeliaSonera, 3 or Telenore, directly or through a payment gateway provider, such as Unwire. The cost of the premium SMS are billed to the customers by the mobile operator. Unlike a normal SMS, part of the charge is paid to the service or content provider. The payout to the service provider varies between SMS number and operator, but up to $45 \%$ of the price is kept by the operator.

SMS payments compete with payment cards cash payment and they are based on the collaboration between mobile operators and content providers or service providers. This is an example of how industries can enter a new market and compete with business clusters. The existing ecosystem has not come up with a directly competing technology, but is defending the market position through lobbing. Furthermore, SMS payments actually solves a bank issue, namely it reduces the use of coins in vending and parking machines.

\subsection{Macro Level Competition - PayPal}

PayPal might be a possible contender of the established payment ecosystem. PayPal was founded in 1998 and has over 120 million active accounts. PayPal accepts payments in 25 currencies, including the Danish Krone. They registered as a bank in Luxembourg. PayPal provide the basic bank services of setting up accounts both for individuals and merchants. It is possible to make payments and financial transactions through web interfaces, mobile interfaces, and e-mail. The growth and expansion of PayPal is based on three-phase strategy. "First, PayPal focused on expanding its service among eBay users in the U.S. Second, we began expanding PayPal to eBay's international sites. And third, we started to build PayPal's business off eBay" (former eBay CEO Meg Whitman). On example, of the expansion strategy is that PayPal are 
providing an API for third party software developers. This is build and defends strategy by PayPal. They are expanding their payment function from the eBay ecosystem to become a global payment provider.

The functionality found in PayPal is making up a technology regime. Similar to payment dongles and SMS payments, PayPal utilizes existing technology components and systems. However, they adopt their offerings to different platforms, from eBay, to the ecommerce sites to mobile ecosystems, such as iPhone and Android. They grow organically and have slowly begun to attack the payment ecosystem. As said before they are collaborating and partnering with different actors in the payment market. For instance, they collaborate with all the major payment cards companies (business clusters), such as VISA, MasterCard. In Denmark they collaborate with a foreign small bank (SEB) to allow PayPal users to transfer money to their PayPal account. Furthermore, they are collaborating with e-commerce firms, by having an API to enable integration between PayPal and e-commerce sites. The current business models of PayPal have components that could challenge existing payment ecosystems.

The reaction towards this potential enemy has been indirect. The established payment ecosystem continues to invest in their existing infrastructure to provide the users with better services than PayPal. For instance, the launch of mobile banks has been huge successes. Dansk Bank used Facebook to involve its customers in the development of their mobile bank. A key resource for the banks in this battle might actually be there local presence and the trust they have built with their customers.

\section{Discussion and Conclusion}

Building on the existing literature on digital ecosystems, this paper develops a complementary perspective on transformation of digital ecosystems by regarding ecosystem transformation as a distributed and emergent process. We illustrate the use of the framework by a study of the digital payment ecosystem.

In the case of the digital payment ecosystem, no single actor holds a position that allows them to rationally design ecosystem transformation. Instead ecosystem transformation can be seen as emerging from the collective positioning of technological innovations in relation to the micro-, meso- and macro-level positioning

Starting at the micro unit level, the payment ecosystem is experiencing the introduction of new technological innovations which challenge the individual members and existing payment technologies. At this level, actors draw on existing technological systems and regimes with compatible technology innovations.

On the meso level, new technologies that are incompatible with existing technologies, but still existing within the same technological ecosystem lead to rival technological systems. This leads to competition between business clusters, as in the case where banks competes against telecom providers with rival SMS payment innovations.

Finally, on the macro level, new technology regimes may emerge that challenge the existing ecosystem. This leads to competition among the ecosystems. PayPal's ecosystem based on internet-technologies rather than the traditional payment IT infrastructure consist an ecosystem challenge to the traditional payment ecosystem. 


\section{$5.1 \quad$ Theoretical Contribution}

This paper contributes towards the explanation of how the fusion-relationship between business and technology in digital ecosystems affects ecosystem transformation. The DETT framework explains the effects of technological compatibility on ecosystem positioning. The horizontal dimension of the framework shows the competitive dimension of ecosystems as rivalry between existing businesses, with its installed base of technology, and new entrants with technological innovations that are trying to enter the market.

The vertical dimension shows the collaborative dimension of digital ecosystems, depicting collaboration between actors on two levels: meso (collaboration in cluster), and macro (collaboration as ecosystem). On the micro-level, individual business units compete with incompatible technologies. On the meso-level, formal and informal strategic networks and alliances are formed as a result of members joining forces in clusters to compete with other clusters of members. On the macro-level, the ecosystem of interdependent members as whole competes with other ecosystems through market collusion strategies based on technology regimes. The vertical dimension also shows how collaboration occurs between the levels through system-, cluster-, regime, and ecosystem collaboration.

\subsection{Practical Implications}

For the growing number of industries being fused with digital technologies, exploiting the specific characteristics of these industries becomes a key challenge for firm success. Here we discuss the implications of our findings on two distinct actors related to digital ecosystem transformation: new entrants and existing members.

In the payment ecosystem case, new entrants come from two distinct sources: startups, and from adjacent industries, such as telecom. The case suggests that traditional members, to a greater extent than new entrants, approach technologies that are compatible with existing technology clusters (systems). New entrants seek to make their entries with technological solutions that are incompatible with existing technology systems, which creates rival competitive systems.

Existing members can take two positions in the blocking of new entrants: to face them on the micro- or meso level. Facing the new actors on a micro-level leads to the acceptance of rival competitive systems. This can be motivated by that new entrants are not direct competitors. Facing new entrants on the meso level yields two options: systemic competition or inclusion in clusters. An example of the first is Danske Bank's collaboration with an external provider for their iPhone application. An example of the latter is the clustered competition of rival systems for SMS payments. Traditional actors (banks) are forced to collaborate to face off a rival system that indirectly threatens existing business. Regardless of level of encounter, the market entry is blocked by increasing level of capital investment in technology required to enter, or by restraining access to specific technology that complements the entrants offering.

Acknowledgements. This work was in part carried out with the support of Copenhagen Finance IT Region (www.cfir.dk) and was funded by the Danish Enterprise and Construction Authority grant number ERDFH-09-0026. 


\section{References}

Adomavicius, G., Bockstedt, J.C., Gupta, A., Kauffman, R.J.: Technology Roles and Paths of Influence. Information Technology and Management 8(2) (2007)

Basole, R.C., Karla, J.: On the Evolution of Mobile Platform Ecosystem Structure and Strategy. Business \& Information Systems Engineering 3(5), 313-322 (2011)

Danmarks-Nationalbank. Betalningsformidling i Danmark. Danmarks Nationalbank, København (2005)

Evans, D.S., Hagiu, A., Schmalensee, R.: Invisible Engines: How Software Platforms Drive Innovation and Transform Industries. The MIT Press, Boston (2006)

García-Marco, F.J.: Libraries in the Digital Ecology: Reflections and Trends. The Electronic Library 29(1), 105-120 (2011)

Garcia-Swartz, D., Hahn, R., Layne-Farrar, A.: The Move toward a Cashless Society. Review of Network Economics 5(2), 175-197 (2006)

Ghazawneh, A., Henfridsson, O.: Balancing Platform Control and External Contribution in Third Party Development. Information Systems Journal (2012)

Hanseth, O., Lyytinen, K.: Design Theory for Dynamic Complexity in Information Infrastructures. Journal of Information Technology 25(1), 1-19 (2010)

Henningsson, S., Zinner Henriksen, H.: Inscription of Behaviour and Flexible Interpretation in Information Infrastructures. JSIS 20(4), 355-372 (2011)

Iansiti, M., Levien, R.: The Keystone Advantage. HBSP, Boston (2004)

Kokkola, T. (ed.): The payment system. European Central Bank, Frankfurt (2010)

Moore, J.: The Death of Competition: Leadership and Strategy in the Age of Business Ecosystems. Harper Business, New York (1996)

Ondrus, J., Lyytinen, K.: Mobile Payments Market: Towards Another Clash of the Titans? In: The 10th ICMB, Como, Italy (2011)

Porter, M.E.: Competitive Advantage: Creating and Sustaining Superior Performance. Free Press, Boston (1985)

Sawy, O.A.E.: The 3 Faces of Is Identity: Connection, Immersion, and Fusion. Communications of the Association for Information Systems 12(1), 588-598 (2003)

Selander, L., Henfridsson, O., Svahn, F.: Transforming Ecosystem Relationships in Digital Innovation. In: 31st ICIS, St. Louis (2010)

Selander, L., Henfridsson, O., Svahn, F.: Capability Search and Redeem across Digital Ecosystems. Journal of Information Technology (2013)

Shane, S.: Technology Regimes and New Firm Formation. Management Science, 1173-1190 (2001)

Stabell, C.B., Fjeldstad, D.: Configuring Value for Competitive Advantage. Strategic Management Journal 19(5), 413-437 (1998)

Tilson, D., Lyytinen, K., Sørensen, C.: Digital Infrastructures: The Missing IS Research Agenda. Information Systems Research 21(4), 748-759 (2010)

Walley, K.: Coopetition. International Studies of Management and Organization 37(2), 11-31 (2007)

Yin, R.K.: Case Study Research: Design and Methods. SAGE, Thousand Oaks (1984)

Yoo, Y., Lyytinen, K., Boland, R.: Innovation in the Digital Era: Digitization and Four Classes of Innovation Networks (2008)

Zammuto, R.F., Griffith, T.L., Dougherty, D.J., Faraj, S.: Information Technology and the Changing Fabric of Organization. Org. Sci. 18(5), 749-762 (2007) 